\title{
Pelas redes da tradução: um estudo do conceito de transcriação, de Haroldo de Campos, no poema "Quisera no meu canto ser tão áspero", de Dante Alighieri
}

Through the web of translation: a study of Haroldo de Campo's transcription concept in the poem "Quisera no meu canto ser tão áspero", by Dante Alighieri

Doutora em Teoria da Literatura (2016) pela Universidade Estadual Paulista Júlio de Mesquita (UNESP) e mestre em Letras pela Universidade Federal da Paraiba (2010). Atualmente é professora Adjunta na Universidade Federal de Rondônia, Linguísticos e Literários - DELL, Vilhena, Rondônia, Brasil.

\begin{abstract}
Ana Carolina Lopes Costa ${ }^{1}$
Universidade Federal de Rondônia, Departamento de Estudos Linguisticos e Literários, Vilhena, RO, Brasil.

\section{RESUMO}

O conceito de tradução aplicado por Haroldo de Campos é uma importante vertente da sua obra. Partindo da noção de Bense, ele defende que a identidade de um texto literário reside na articulação das redes de informação estética, enfatizando que cada texto possui uma ordenacão singular de signos. Ao tradutor cabe ler e reescrever essa informação, com os olhos firmados na tradução entendida como crítica e criação (CAMPOS, 2006). Transgressiva, a perspectiva de tradução luciferina (CAMPOS, 2005, p. 180) baseia-se em um gesto de insubmissão ao conteúdo do texto de partida, pensando o exercício de tradução do signo em si. A ideia é tornar o texto de chegada em uma espécie de original, transformando o tradutor em "criador". Aliás, para Campos, essa seria a única saída, principalmente, no caso da poesia. Esse artigo tem, pois, por objetivo, o estudo dessa vertente de tradução no poema "Quisera no meu canto ser tão áspero", de Dante Alighieri, transcriação conduzida por Campos. A recriação da "lira pétrea" esquema singular de rimas que culmina no isomorfismo: mulher/pedra - a melopeia posta a serviço da violência da linguagem etc., convidam-nos a refletir sobre o método de tradução de Campos, percebendo aqui o poeta que habita o fazer do tradutor

Palavras-chave: Tradução. Haroldo de Campos. Poesia. Transcriação.

\section{ABSTRACT}

The translation concept applied by Haroldo de Campos is an important part of his work. Parting from Bense's notion, he defends that the identity of a literary text resides in the articulation of the networks of aesthetic information, emphasizing that each text has a singular order of signs. It is up to the translator to read and rewrite this information, with eyes fixed on the translation understood as criticism and creation (CAMPOS, 2006). The transgressive perspective of luciferin translation (CAMPOS, 2005, p. 180) is based on a gesture of insubmission to the content of the source text, in regards to the exercise of the translation of the sign itself. The idea is to turn the translated text into a kind of original, transforming the translator into a "creator". Furthermore, to Campos this would be the only way, especially when it comes to poetry. The goal of this article, therefore, is the study of this translation aspect in the poem "Quisera meu canto ser tão áspero", by Dante Alighieri, a transcription conducted by Campos. The recreation of the "stony lyre" which is a singular scheme of rhymes that culminates in isomorphism: woman/stone - the melopoeia posted as a strong use of language, etc., invite us to reflect about Campos's translation method, perceiving the poet who inhabits the translator's doing.

Keywords: Translation. Haroldo de Campos. Poetry. Transcription.
\end{abstract}




\section{Tradução e Plagiotropia: convergências ${ }^{1}$}

Flamejada pelo rastro coruscante de seu Anjo instigador, a tradução criativa, possuída de demonismo, não é piedosa nem memorial: ela intenta, no limite, a rasura da origem: a obliteração do original. A essa desmemória parricida chamarei de 'transluciferação'

(CAMPOS, 2005, p. 209).

\subsection{Campos e Benjamin}

D ra Campos (2005), tradução é transluciferação, transluminação². A tradução não é servil, submissa, seu objetivo primordial é capturar a informação estética do texto-base, recriando-a no texto traduzido. A consequência disso é que o tradutor não deve apenas conhecer uma língua, mas ser um excelente leitor de poesia, em um primeiro momento, para depois, como poeta, reescrever o texto em um idioma diferente, submetendo-o à 'violência' do contato com a língua estrangeira. Uma das tônicas que reforça a ideia de Campos está no texto "Die Aufgabe des Uebersetzers", de Benjamin: a tradução deve pautar-se na transmissão de "uma forma", caso contrário corre um sério risco de, buscando uma suposta fidelidade, focar-se na "transmissão inexata de um conteúdo inessencial" (BENJAMIN, 2011, p. 102). Ainda, segundo Benjamin:

O que 'diz' uma obra poética? O que comunica? Muito pouco para quem a compreende. 0 que lhe é essencial não é comunicação, não é enunciado. E, no entanto, a tradução que pretendesse transmitir algo não poderia transmitir nada que não fosse comunicação, portanto, algo de inessencial. Pois é essa mesmo uma característica distintiva das más traduções (2011, p. 102).

\footnotetext{
Este artigo é uma extensão de estudos iniciados em nosso Mestrado e Doutorado

2 "Essa cadeia de neologismos exprimia, desde logo, uma insatisfação com a ideia 'naturalizada' de tradução, ligada aos pressupostos ideológicos de restituição da verdade (fidelidade) e literalidade tradução, ligada aos proșão um presugicos de restição da verdade (fidelidade) e literalidade (subserve cina da operação tradutora" (CAMPOS, 2013, p. 79).
}

Recuperamos aqui o título original do ensaio de Benjamin, comumente traduzido por "A tarefa do tradutor", em razão das nuances semânticas que percorrem o substantivo "Aufgabe" e que nos auxiliam na compreensão benjaminiana de tradução. Segundo nota de Gagnebin (2011, p. 101), ao recuperar o verbo "aufgeben", em seu uso intransitivo: "ich gebe auf - eu "renuncio, desisto, me entrego", teríamos outros sentidos para o substantivo "Aufgabe", como: "proposta", "renúncia" e "desistência". Se tomarmos alguns destes sentidos para a noção de "tarefa", compreenderemos que, para Benjamin, o tradutor apresenta uma proposta, a partir da renúncia à transmissão do que está comunicado, o que é significado, buscando o nível da "não comunicação", assim, sua tradução é uma possibilidade, não barrando o horizonte no qual poderão surgir outras versões do mesmo texto: o tradutor, acima de tudo, é um mensageiro, o "ángelos" portador ${ }^{3}$. Para Benjamin, a tradução injeta a renovação na "vida do original", como algumas boas-novas, trazidas pelos anjos, provocavam intensas modificações nas histórias dos agraciados: "Nelas [nas traduções], a vida do original alcança, de maneira constantemente renovada, seu mais tardio e mais abrangente desdobramento" (BENJAMIN, 2011, p. 105). Essa vida, fôlego de criação, é compatível com a noção de tradução como transcriação defendida por Campos (2006): traduzir é reescrever a informação estética do texto de partida no texto de chegada. Isto implica dizer que, em alguns momentos, certos sentidos incrustados nos vocábulos e expressões vocabulares serão modificados, relegados a um segundo plano, preconizando-se, muitas vezes, as nuances melopaicas e fanopaicas da linguagem, pondo em discussão a ideia de "fidelidade". Lemos ainda Benjamin (2011, p. 107-108):

Campos (2005, p. 179) diz: “De fato, no entender do próprio W. Benjamin, cabe à tradução uma função angelical, de portadora, de mensageira”. 
Pois na sua "pervivência" (que não mereceria tal nome, se não fosse transformação e renovação de tudo aquilo que vive), o original se modifica. Existe uma maturação póstuma mesmo das palavras que já se fixaram: o que à época do autor pode ter obedecido a uma tendência de sua linguagem poética, poderá mais tarde esgotar-se; tendências implícitas podem surgir como novas da forma criada.

O processo de tradução na compreensão de Campos (2006), no que esse exige de recriação de informação estética, pede do tradutor, além da decifração dos códigos profundos que regem a produção estética da linguagem, a capacidade de transcriação desses códigos no idioma de chegada; o tradutor é, pois, criador, noção também presente em Benjamin (2011, p. 117): "A tarefa do tradutor é redimir, na própria, a pura língua, exilada na estrangeira, liberar a língua do cativeiro da obra por meio da recriação". Segundo Campos (2013, p. 98), Benjamin vê na tradução de poesia: "uma tarefa, dirigindo-a ao escopo para o qual está teleologicamente [...] vocacionada: atestar [...] a afinidade [...] entre as línguas".

Contudo, alargando a função da tradução como a do anjo veiculador de mensagem desenvolvida por Benjamin (2011), para Campos (2005), o tradutor é o anjo insubmisso, audacioso, que subvertendo a suposta fidelidade, vê na transgressão a possibilidade de usurpação do texto traduzido: sua reescritura almeja dialogar de igual para igual com o modelo, existir ao lado dele como um original. $O$ ato de traduzir está, pois, carregado da hýbris, da audácia também mefistofélica. Ao romper a ponte que une "os limites sígnicos" (CAMPOS, 2005, p. 180), o tradutor impõe, pela sua criação, um texto que não é mais uma "cópia" de um original, mas que se põe como um original.

Nesse impulso reside o pacto mefistofélico, a tradução, também no entender de Campos, para ser autenticamente fiel à informação estética, deve ser infiel a esse "conteúdo inessencial". O tradutor criativo não é apenas transmissor de mensagem, mas acima de tudo criador de informação, e então insubmisso e transgressor. Quando Campos (2005) propõe a usurpação do status do texto original, ecoa a figuração do gesto diabólico, oblíquo porque transgressor em sua essência. Ao contrário do que se pode pensar, isso não produz uma contradição na proposta da tradução, no sentido em que anula a voz do autor traduzido, ao invés disso, entende-se que nenhuma tradução pode ser imparcial, de maneira que, do seu resultado, emerja apenas a voz do autor traduzido, negando o sujeito tradutor. Assim como a leitura de um texto sempre leva consigo o mundo intelectual do leitor, não existe tradução "inocente", todo ato de traduzir leva em seu cerne a singularidade de um tradutor. Isso fica bastante patente em toda extensão da obra de Campos, já que, na grande maioria dos casos, escolhe apenas "pedras-de-toque", como ele mesmo diz, ou fragmentos de textos para transcriar. Essas escolhas vão tecendo o longo tecido que perpassa sua obra, construído por proposições críticas, criativas e por sua noção de tradução. E é nessa linha que as traduções de Campos apresentam sua leitura de uma obra, autorizando, até um estudo do modus operandi de sua criação e crítica a partir de uma tradução:

Quanto à contribuição relevante de Meschonnic, resumida na proposição 10 , segundo a qual a tradução é 'escritura duma leitura-escritura, aventura histórica dum sujeito', poderíamos reescrevê-la paronomasticamente [...] como TRADUTOR: TRADITOR, pensando na tradução como tradição do passado no presente (CAMPOS, 2013, p. 94).

Aqui, pois, ecoa nossa afirmação de que a tradução contém em si um ato de leitura singular, carregando a idiossincrasia do sujeito que traduz, sua perspectiva e a leitura histórica do texto traduzido e mesmo sua concepção de literatura. No caso de Campos a coisa se adensa, já que seu método de transcriação pode ser encontrado em sua poesia e, mesmo, na 
sua crítica. Campos (2013, p. 13) prefere partir, por exemplo, da noção de "paramorfismo" dos textos, no lugar de "figuração" ou "teoria da cópia" instituídas pela necessidade de "assimilação do sentido do original" ou aproximação exata do conteúdo. 0 prefixo "para" assemelha-se à noção de paródia como canto paralelo - preconizada por Campos - como textos que caminham lado a lado: "A exatidão (Genauigkeit) no traduzir se regula não por essa busca imprecisa de 'similaridade' no plano do significado, mas pelo resgate da 'afinidade'” (CAMPOS, 2013, p. 102).

Não haveria texto ou sentido original antes de uma leitura. Aquilo que chamamos original se estabelece e se modula segundo as diversas interpretações de um texto, que dessa maneira perde qualquer essência ou significado intrínsecos. 0 sentido do original é o sentido que lhe atribui um leitor ou uma determinada situação interpretativa, um determinado contexto de leitura. $\mathrm{O}$ argumento pode ser resumido da seguinte maneira: não existe original antes de sua tradução; é a tradução que, de alguma maneira cria seu original (SISCAR, 2013, p. 168-169).

\subsubsection{O conceito de tradução na obra de Campos}

A obra de Haroldo de Campos, pensada como um organismo, está percorrida por uma espécie de sistema circulatório, no qual os vasos sanguíneos nutrem e trocam material entre as suas partes (MACHADO, 2003). Falamos aqui de sua performance poética tocada por sua crítica, de sua crítica explorando temas e formas de sua criação, e do seu método de tradução ancorado em uma dupla perspectiva crítica e criativa. Com o olhar fixo nessas relações, percebemos um centro irradiador, um procedimento que se faz presente nestas três vertentes de sua produção, isto é, a prática da releitura da tradição e seu método executor: a plagiotropia. Ao termo, Campos doa uma curta nota em seu ensaio "A escritura Mefistofélica", em Deus e o Diabo no Fausto de Goethe, para explicar a maneira diferenciada de leitura da tradição, da qual se valeu Goethe em Fausto:
A plagiotropia (do gr. plágios, oblíquo; que não é em linha reta; transversal; de lado), tal como a entendi no curso que ministrei na primavera de 1978 na Universidade de Yale sobre a evolução de formas na poesia brasileira se resolve em tradução da tradição, num sentido não necessariamente retilíneo. Encerra uma tentativa de descrição semiótica do processo literário como produto do revezamento contínuo de interpretantes, de uma "semiose ilimitada" ou "infinita" (Peirce; Eco), que se desenrola no espaço cultural (CAMPOS, 2005, p. 75).

Parte do inventário vocabular da botânica, plagiotropia é crescimento diferente que o caule de uma planta apresenta, quando vai dispensando a verticalidade, e adotando o desenho dos galhos; desviado da ortotropia, o caule cresce vergado para um lado (WENDLING, 2003). Assim, o vegetal, em processo plagiotrópico, impõe ao seu corpo um desvio, rechaçando um desenvolvimento vertical. Campos (2005, p. 75), recuperando a etimologia de plagiotropia, acentua o oblíquo, a não linearidade e a transversalidade implicados na notação grega de plágios. Ao tomar o modus operandi deste acontecimento do plano biológico e imprimi-lo à floração da literatura, ou seja, à sua evolução das formas, Haroldo de Campos nos aponta uma outra compreensão: ao invés de seguirmos uma linha ortotrópica, aquela que retoma a tradição apenas diacronicamente, julgando anacrônica qualquer aproximação fora do contexto histórico, optamos pelo desvio criativo: uma busca da aproximação de textos afastados por tempos e estilos literários, um ato que permite repensar os cânones:

Em matéria de literatura, é sempre bom colocar-se, de quando em quando, a diacronia em pânico. '0 pulo tigrino no passado', como o descreveu Walter Benjamin com faro dialético. Tratamento de cura preventiva contra o respeito reverencial dos historiadores de ofício. Que sempre virão outra vez arrumar nas prateleiras os autores e obras temporariamente deslocados dos nichos 'gloriosos', pois têm ouvidos à prova de abalos sísmicos, paciência cadaverosa e uma suspicácia vaticana diante do milagre (CAMPOS, 2013, p. 10). 
A expressão "pôr em pânico" é bastante substancial para afirmarmos que os exercícios crítico, poético e o método de tradução de Campos aproximam poéticas a partir da obliquidade, chamando ao pensamento sincrônico, a plasticidade do desvio, como no termo grego "plágios". "Pôr a diacronia em pânico" é, pois, inserir na estabilidade plana de uma linha evolutiva, a abertura da instabilidade, principalmente no que o vocábulo "pânico" contém de "medo" e "ansiedade". A desestabilização do sistema fica restrita ao primeiro momento, para que, em um segundo tempo, sejam propostas novas organizações, sincronizando dicções poéticas a partir do leme da obliquidade. Mutatis mutandis, nesta linha, o raciocínio plagiotrópico também se propaga, ao negar a linearidade, alavancado por uma flexibilidade de raciocínio para os lados: é a lógica das ramificações, provocando amálgamas criativos no âmbito da tradição. Essa ideia é reforçada, mais ainda, na medida em que se compreende o processo de interação como conversas entre estruturas:

Na poesia concreta brasileira temos um exemplo frisante de contestação até programática do dogma da linearidade (desde os primeiros manifestos, a culminar no Plano Piloto, de 1958: 'estrutura espácio-temporal, em vez de desenvolvimento meramente temporístico-linear'), assim como de manipulação criativa dos efeitos da simultaneidade para a produção de textos destinados a uma leitura não linear, mas plúrima (CAMPOS, 2006a, p. 118).

Buscando a aproximação de estruturas, estamos em terreno análogo à plasticidade assumida pela linha oblíqua, plagiotrópica: ambas, tradução e plagiotropia, se constituem como atos de transgressão. A segunda, no seu rompimento com a linearidade imposta à compreensão de uma tradição, instaura, pelo desvio, um movimento constelar síncrono-diacrônico. Reverbera-se, pois, um modus operandi que também reside na ideia de transgressão presente na tradução luciferina, fato que não seria estranho a uma teoria da tradução que se põe como crítica e como criação. 0 ato de transgredir engloba, assim, a usurpação da origem e a negação da tradução de um "conteúdo inessencial":

Em vez de render-se ao interdito do silêncio, o tradutor-usurpador passa por seu turno, a ameaçar o original com a ruína da origem. Esta, como eu a chamo, a última hýbris do tradutor luciferino: transformar, por um átimo, o original na tradução de sua tradução. Reencenar a origem e a originalidade como plagiotropia: como 'movimento infinito da diferença' (Derrida); e a mímesis como produção mesma dessa diferença (CAMPOS, 2013, p. 56).

O impulso plagiotrópico é capaz de reencenar essa origem enquanto obliquidade, diferença, através de um reposicionamento da tradição, o que permite a "pervivência" da obra no campo de uma literatura. Na transluminação, o texto traduzido é o resultado de um ato que refaz a origem do texto base; o produto final, assim, não pode mais constituir-se como reflexo fiel, mas impondo-se como diferença, tem uma identidade própria. Este, agora, ser individual usurpa/põe em questão o status do que é ser "original". A relação aqui não é isomórfica: forma/conteúdo, mas paramórfica, no sentido em que os textos andam 'ao lado de'. É importante enfatizar que a empresa luciferina não se impõe como versão única, mas posiciona-se enquanto possível originalidade, abrindo o horizonte para as possibilidades de outras traduções, "restituindo o campo cambiante do provisório" (CAMPOS, 2013, p. 56).

Percebamos a ressonância entre os campos da tradução e da crítica plagiotrópica, quando Campos associa aquela à alegoria - no sentido em que é trabalhada por Benjamin - quando esta provoca uma ruptura na "unicidade" do símbolo. O ponto de convergência do pensamento está no processo de rompimento de uma harmonia e seu consequente bloqueio do "sentido definitivo". O que se tem é a reconstrução de um panorama literário, 
que não deve ser reverenciado como cânone, bloco definitivo, mas que, sob o signo da obliquidade, pode fazer pontes sincrônicas entre autores, construindo, assim, uma cadeia de "pervivências". Vista através do prisma da tradução criativa, quando permite o revisar de um padrão de leitura de um texto dentro de uma tradição, o tradutor, a partir de uma noção específica de história, instaura o status da possibilidade:

[...] Assim como as 'monstruosas' traduções hoelderlinianas ameaçam os originais com a corrosão de toda garantia de restituição do sentido (Sinnwiedergabe), também a alegorese 'profana' a unicidade harmônica do símbolo, arruína a linearidade do sentido definitivo e permite, mais adiante, compreender a história como pluralidade sufocada e a historiografia como instância de ruptura e possibilidade de tradução transgressora (CAMPOS, 2013, p. 59).

Postas essas questões, ratificamos a necessidade da compreensão do método de tradução de Haroldo de Campos em uma noção global, noção esta que permita abarcar toda arquitetura de sua obra. Compreendido como mola propulsora capaz de renovar a tradição, se voltarmos à questão do make it new poundiano, os textos recriados fomentam a dinâmica fundamental à saúde da Literatura, evitando o empedramento do motor vivo da novidade que permanece novidade.

\section{Removendo pedras: a dama empedernida de Dante Alighieri e Campos}

Antes de pensarmos o processo de transcriação na prática, faz-se necessária uma pequena contextualização, de modo que possamos compreender as raízes que inspiraram Haroldo de Campos em seu percurso pela obra de Alighieri. Nesse introito, cabe a nós uma volta aos tempos da poesia provençal, já que o poeta italiano, no poema "Quisera no meu canto ser tão áspero", recria o temário das cantigas de amor figurado na Dama sans merci (SPINA, 1991), quando pratica o isomorfismo mulher/pedra. A preocupação com o trato poético vem de longe, sendo fruto de uma prática que também tem raízes na poesia de Provença, por exemplo com um dos seus principais representantes: Arnaut Daniel, citado por Alighieri o na Divina Comédia"4. Aliás, é no século XII que, segundo Spina (1991, p.17), temos a "base" do lirismo europeu na moderna Europa: "Os primeiros capítulos da história literária da moderna Europa foram escritos, no curso do século XII, pelos trovadores da Provença".

A Provença compreendia toda a civilização do "Languedócio, área entre o Mediterrâneo e o Maciço Central, os Pireneus e a fronteira italiana" (SPINA, 1991, p. 17). Augusto de Campos (2009, p. 10) chama atenção para o apuro técnico da poesia provençal: "há [...] a tecnologia poética, o trabalho de estruturação e de ajuste de peças do poema [...] [que] assinala um dos mais altos momentos da poesia no sentido da apropriação do instrumento verbal e de sua adequação ao dizer poético".

Um dos vetores utilizados para alcançar essa poesia de grande vulto foi, sem dúvida, a aproximação efetuada com a música. Pound (1927 ou 1928 apud CAMPOS, 2009, p. 40) apontará a produção dos troubadours do Sul como "uma arte entre a literatura e a música", e Augusto de Campos (2009, p. 40) dirá:

[...] uma técnica de alta precisão no ajuste de palavra ao som. Arte complexa, que não visava apenas encantar com agradáveis efeitos melopaicos, mas, muitas vezes, a instigar e provocar o ouvido com dissonâncias, com entrechoques das palavras, do som e da linguagem.

${ }^{4}$ Purgatório, capítulo XXVI, verso 140 . Um pouco antes, no verso 117 o poeta provençal é categorizado nas palavras de Guinizelli, também personagem da Divina Comédia, "miglior fabbro del parlar materno" ou "melhor artífice da língua materna". 
Sobre isso defende Pound (1927 ou 1928 apud CAMPOS, 2009, p. 41): "E Arnaut foi o melhor artista entre os provençais [...] de sorte que ele ensinou muito a Messire Dante Alighieri [...]". Reiterando Pound, Haroldo de Campos (1998, p. 20) - em Pedra e Luz na poesia de Dante - ao mencionar os poemas da fase petrosa, comenta: "houve uma tomada de consciência e um aproveitamento da mais inventiva linhagem provençal - a do trovador Arnaut Daniel". No famoso poema de Daniel, "L'aura amara", por exemplo, podemos encontrar algumas tônicas que também estarão presentes em "Quisera no meu canto ser tão áspero", nosso texto em tela. Tematicamente, a mulher do ânimo de pedra, irredutível ao amor de seu admirador, está presente em versos como: "E eu sofro a sorte:/ dizer louvor/ em verso/ só por aquela/ que me lançou do alto/ abaixo, em dor/ má dama que me doma". A dama má está tão distante que é quase "uma miragem", o eu trovador é "pagem" do Amor, pois é torturado por esse: "é inútil tor/turares o teu pagem"; e é "combatedor converso" e "prisioneiro".

Do ponto de vista formal, não deixaremos de mencionar o criativo jogo melopaico do título: L'aura (o ar) e Laura (o nome da dama), a dama amarga, que depois ressurgirá na expressão "bela pedra", verso de "Quisera no meu canto ser tão áspero". O trabalho com a camada sonora está posto em toda a estrutura complexa do poema de Daniel. Sobre isso explica Augusto de Campos:

Além das 7 rimas terminais, há, em cada estrofe, mais 10 rimas internas, totalizando, portanto, 17 rimas [...] Rima-se, pois, essencialmente, de estrofe a estrofe, a primeira linha da primeira estrofe com a primeira das demais etc., embora as rimas se entrelacem em cada estância através de um jogo sutil de onomatopeias [...] que, no dizer de Pound, é capaz de transmitir "o som do irado chilrear dos pássaros no outono" (CAMPOS, 2009 , p. 43).

Notamos, portanto, que a retomada da linha inventiva de Daniel dá-se, em Alighieri, principalmente no trabalho do tecido melopaico de sua lira pétrea, provocando uma imbricada costura entre significantes e significados. Seguindo um percurso evolutivo, é interessante notar como esse tipo de trabalho, constante em "Quisera no meu canto ser tão áspero", será aproveitado para configurar a chamada "fala de cor escura”, presente nos versos do Inferno:

[...] A relevância desta questão em Dante pode ser verificada no círculo dos traidores do Inferno, onde a iconografia pétrea encontra ecos: a atmosfera é gélida, 'água que se converte em vidro', faz frio, os personagens apresentam uma palidez lívida, a cor é triste. 0 canto XXXII abre-se com uma inspiração inconfundivelmente pétrea: 'Se eu tivesse rimas ásperas e roucas...' que ecoa literalmente o início da quarta das Rimas Pétreas ('Quisera no meu canto ser tão áspero') e confirma a intenção de Dante: a correspondência do tema tratado (a traição no Inferno, a asperidade da mulher das pedrosas) [...] (LOMBARDI, 1998, p. 13, grifos do autor).

A linha isomórfica da fala de cor escura nascerá, primordialmente, com o conjunto das quatro canções que compõem a lira pétrea. A expressão foi cunhada pelo dantólogo napolitano Vittorio Imbriani, e serve para ilustrar a "fusão metamórfica" - nas palavras de Campos (1998, p.19) - Mulher/ Pedra. O que temos aqui é um exemplo claro de conteúdo mimetizado na forma, fator que não passa despercebido e aguça a atenção do Haroldo tradutor. Para Contini (1946 apud CAMPOS, 1998, p. 20), a veia pétrea é "o nexo que une as líricas mais tecnicistas de Dante, nas quais a energia léxica e a raridade rítmica se transformam, a modo de conteúdo, no tema da dama áspera, do amor difícil". É interessante notar como o Haroldo crítico, por outro lado, explica sua escolha pelo poema da literatura italiana:

Atualíssimas na construção e no despojamento, as rime petrose marcam um ápice na criação linguística dantesca, exigindo do poeta, empenhado na tomada de posse, via palavra, do "real não pacífico", invenções formais extremadas, que pudessem corresponder com justeza a esse seu 'sentimento do real difícil em si, posto como objeto' (CAMPOS, 1998, p. 21). 
A ênfase na atualidade da construção e a presença das invenções formais extremadas excitam, pois, o Haroldo tradutor-criador. Para ele quanto mais difícil melhor: "Quanto mais inçado de dificuldades esse texto, mais recriável, mais sedutor enquanto possibilidade aberta de recriação (CAMPOS, 2002, p. 35) e ainda: "A tradução de poesia é antes de tudo uma vivência interior do mundo e da técnica do traduzido" (CAMPOS, 2002, p. 43). Lombardi (1998, p. 15) comenta: "Haroldo vê a tradução como superposição de extratos intertextuais, percorrendo um caminho que é duplo: o da prática e o da reflexão sobre sua própria prática [...]".

\subsection{0 poema transcriado}

"Quisera no meu canto ser tão áspero" faz parte de um conjunto de traduções publicadas em Pedra e Luz na Poesia de Dante (1998). Repetindo o modelo de outros livros seus, Campos acompanha suas versões dos poemas de Alighieri do texto-base em língua original, permitindo ao leitor, conhecedor da língua italiana, o cotejo. Somada ao texto em italiano, cada solução mais arrojada está explicada num conjunto de notas, algo interessante para quem deseja refletir sobre o processo e caminho percorrido pelo tradutor. Comentando suas escolhas, diz:

Na tradução dos poemas deste ciclo, procurei, dentro do conceito de tradução como criação e como operação crítica, replicar, quanto possível, aos desafios do original. As notas explicativas indicam os passos em que fugi à letra das petrose e as interpretações que dei a certos trechos, as opções enfim, do tradutor preocupado em ser mais fiel à invenção como algo vivo do que ao dogma do significado literal, tantas vezes esterilizante (CAMPOS, 1998, p. 24).

É com esse espírito que Campos traduz a dureza da dama em discurso áspero e rouco, carregado de sons que se batem:
QuiseRa no meu canTo seR Tão áspero como é nos aTos esTa Bela PeDRa

Que a ToDa hora impetra maior DuReZa e essência ainDa mais Crua $[\ldots]$

QuiseRa vê-lo assim fenDeR no centro o coRação à CRuel Que me malTRaTa". (CAMPOS, 1998, p. 55).

A combinação de bilabiais, linguodentais, velares e vibrantes vai dando roupagem a um tipo de som marcado, forte e explosivo de "essência ainda mais crua", colaborando para confirmar a atmosfera de descontentamento e raiva do amado não correspondido. 0 que temos aqui é figuração em som do desgosto amoroso: "[...] uma forma realista de insatisfação amorosa, acompanhada pela dissonância acústica e pela mais renhida condensação semântica" (CAMPOS, 1998, p. 21).

Buscando, deste modo, alcançar esse espírito em sua tradução, Haroldo utilizará a iteração das vogais de tonalidade escura, como no verso: "NãO achO escUdO - tUdO ela rebenta". Esses sons são reforçados pela atmosfera lamuriosa posta nas aliterações e vogais nasais: "AtINge a todos, rOMpe qualquer arma / cOMo, assIM, MINha mENte, tÃO [...]" e os pares de rimas: esconda/ponta/onda/afronta, tecendo uma malha sonora de lentidão, um verdadeiro canto de lamentos que percorre toda a extensão dos versos:

Não acho escudo - tudo ela rebenta -

Nem sítio que do seu olhar me esconda; Que, como flor na ponta,

Assim da minha mente está por cima.

Tão pouco do meu mal parece atenta, Como o barco do mar que não faz onda; [...] (CAMPOS, 1998, p. 55). 
É interessante mencionar o esquema rímico adotado por Campos em sua tradução. Ele aponta o uso de "zonas fônicas" compostas por pares de rimas consoantes, toantes e imperfeitas, ao contrário do original que contém rimas consoantes. Campos justifica sua opção por meio das "modernas pesquisas em torno da rima irregular" e ainda da "Gestalt sonora" que percorre o poema. A modificação do esquema de rimas é justificada ainda pelo tema da "aspereza dissonante", posta no par mulher-pedra ou no "parlar aspro" das palavras (CAMPOS, 1998, p. 62).

Para os estudiosos da obra de Alighieri, a fase da lira pétrea é carregada pelo sentimento de trabalho árduo com o discurso poético, buscando fazer do som um eco do significado: "Inusitadas ousadias formais, novos esquemas rítmicos, imagens vivíssimas e quase brutais, comparações audazes, palavras procuradas, versos martelados, sons ásperos [...]" (VICINELLI, 1950 apud CAMPOS, 1998, p. 21). Como pedra-de-toque deste trabalho de Aliguieri, exemplificamos os versos: "perchè non ti ritemi/ sì di roderni il core a scorza a scorza[...]", Campos traduz como "então por que não temes/ comer-me o coração escama a escama [...]. O par "ritemi - roderni", costurando uma onda melopaica que percorre os versos e vai muito além da rima, torna-se "temes - comer-me", replicando aliteração em [m] e assonância em [e].

Para o amante que reclama seu amor ignorado, o pano de fundo é triste, melancólico, carregado de tonalidades disfóricas: "Treme meu coração sempre que nela/ penso em recinto onde outro olhar me cruza,/ [...]/ Com os dentes de Amor já me mastiga:/ à mente me castiga". Nessa versão, Campos procura ainda enfatizar a dama que alimenta a desordem, de pulso violento, certeiro e imprevisível:

[...] e ela mata, e dos golpes dessa sua

mira mortal ninguém se guarda ou livra

com asas ela os vibra, atinge a todos, rompe qualquer arma: dela não sei, inútil dar alarma

$[\ldots]$

Ó angustiante, despiedosa lima (CAMPOS, 1998, p. 55).

Após construir uma melodia de insatisfação, em virtude do amor recusado - "tão pouco do meu mal parece atenta,/como o barco do mar que não faz onda/ esta facínora homicida e ladra,/ ai!, que por mim não ladra" - o poema chega ao estopim, posto num sentimento sádico de vingança. Campos capta isto, optando por:

QuisERa vê-lo assim fendER no centro o coRação à cRUel Que me maltrata

$[\ldots]$

Se eu lhe apanhaR as TRanças uma vez $[\ldots]$

não sERei piedoso nem cortês

no meu BRinquedo de uRso

$[\ldots]$

Canção, paRTe ceRTeiRa àQuela dama

[...]

vaRa-lhe o coRação feiTo uma lança

alto PRêmio se colhe na vingança (1998, p. 59-61).

A temática reiterativa da coita amorosa medieval ganha em Alighieri, saindo do campo apenas do "fator externo" (CANDIDO, 2006) - o status de "fator interno" (CANDIDO, 2006) confluindo num mar de sons imbricados em significados:

De fato, a idealização da mulher amada (Beatriz na Vita Nuova), regida pelas convenções do "amor cortês" [...] servida pela delicadeza da linguagem, cedera lugar, nas rime petrose, à forma realista de insatisfação amorosa, acompanhada pela dissonância acústica e pela mais renhida condensação semântica [...] ocorre mesmo uma antecipação literária do 'sadismo' amoroso, uma explosão de sensualismo frustrado que se compraz na vingança [...]. (CAMPOS, 1998, p. 23) 
Campos (2013, p. 62), lendo, Variations sur les Bucoliques, comenta que reside em Valéry "a ideia da literatura como uma operação tradutora permanente - escrever é traduzir -, logo a relativização da categoria da originalidade em favor de uma intertextualidade generalizada". É mister lembrarmos que a noção da literatura como "operação tradutora" aparece em nota em Deus e o Diabo no Fausto de Goethe. Campos vai relacionar esse ponto com a noção de paródia como canto paralelo, através da intertextualidade, e acrescenta nesse raciocínio a ideia de que essa intertextualidade generalizada é oblíqua, plagiotrópica. Vejamos:

A plagiotropia [...] se resolve em tradução da tradição, num sentido não necessariamente retilíneo. Encerra uma tentativa de descrição semiótica do processo literário como produto do revezamento contínuo de interpretantes [...]. Conjuga-se com minha concepção de operação tradutora como capítulo por excelência de toda possível teoria literária (e literatura comparada nela fundada) (CAMPOS, 2005, p. 75-76).

Para Valéry, o exercício de criação de linguagem implicado no fazer poético é também uma operação de tradução: traduzir o falar cotidiano em arte linguística, a partir da manipulação consciente dos códigos da língua (CAMPOS, 2013, p.66-67). Percebemos que surge nesse diálogo Campos/ Valéry, uma das pontas do tecido que forma a concepção do primeiro de tradução como criação. Campos (2013, p. 74) assinala ainda que, para Valéry, traduzir é "discutir por analogia", ou seja, refletir sobre os ditames e liames empregados nas redes criativas que formam a linguagem do poema a ser traduzido, e as possibilidades de recriá-lo em uma transcriação: "discutir por analogia não era, pois, [praticar um exercício de] mera cópia ou imitação, mas significava algo ativo e transformador" (CAMPOS, 2013, p. 74).

A percepção da atividade e da transformação, quando pensadas junto ao conceito de tradução, impulsiona a ideia da tradição como coisa viva, algo caro ao Haroldo tradutor, criador e crítico. Entendendo que, no poema, a fragilidade da informação estética é máxima (CAMPOS, 2006) - falamos aqui da construção sígnica presente - o tradutor deve ser capaz de conseguir ler e reescrever esta informação singularizada no idioma de chegada, ciente da máquina que proporciona a plurissignificação. Nesta esteira, ao tradutor, é permitida uma manipulação com o espaço da língua, análoga ao exercício do poeta, quando, como "designer da linguagem", cria novas significações. Campos, assim, conduzido pelas setas certeiras da dama de pedra vai transcriando o universo da isomorfia dantesca, tensionando estruturas. As múltiplas camadas de linguagem são seu guia pelos caminhos ásperos de um canto que vibra, levantando as asas da perene renovação.

\section{Referências}

CANDIDO, Antonio. Literatura e Sociedade. Rio de Janeiro: Ouro sobre o azul, 2006.

BENJAMIN, Walter. Escritos sobre Mito e Linguagem. Tradução Susana Kampff Lages e Ernani Chaves; organização, apresentação e notas de Jeanne Marie Gagnebin. São Paulo: Duas Cidades/Ed. 34, 2011

CAMPOS, Haroldo de. Deus e o Diabo no Fausto de Goethe: marginalia fáustica (leitura do poema acompanhada da transcriação em português das duas cenas finais da Segunda Parte). São Paulo: Perspectiva, 2005.

CAMPOS, Haroldo de. Metalinguagem e outras metas. 4 ed. São Paulo: Perspectiva 2006. (Coleção Debates)

CAMPOS, Haroldo de. Pedra e luz na poesia de Dante. Rio de Janeiro: Imago, 1998.

CAMPOS, Haroldo de; CAMPOS, Augusto de; PIGNATARI, Décio. Teoria da Poesia Concreta: textos críticos e manifestos 1950-1960. 4. ed. São Paulo: Ateliê Editorial, $2006 a$.

CAMPOS, Haroldo de. Transcriação. Organização Marcelo Tápia e Thelma Médici Nóbrega. São Paulo: Perspectiva, 2013. 
CAMPOS, Augusto de. Verso, reverso e controverso. São Paulo: Perspectiva, 2009.

LOMBARDI, A. Transumanar, transcriar. In: CAMPOS, Haroldo de. Pedra e luz na poesia de Dante. Rio de Janeiro: Imago, 1998.

MACHADO, I. Escola de Semiótica. São Paulo: Ateliê Editorial, 2003.

SPINA, S. A lírica trovadoresca. São Paulo: Edusp, 1991.

SISCAR. M. Jacques Derrida: literatura, política e tradução. São Paulo: Autores Associados, 2013.

WENDLING, I. et al. Influência da minieataquia seriada no vigor de minicepas de clones de Eucalyptusgrandis. Rev. Árvore, Viçosa, v. 27, n. 5, Oct. 2003. Disponível em: www.scielo.br/scielo.php?script=sci_arttext\&pid=S0100-67622003000500003. Acesso em: 21 ago. 2012. https://doi.org/10.1590/s0100-67622003000500003

Recebido em: 10/10/2018.

Aprovado em: 4/1/2019.

Publicado em: 20/6/2019. 